\title{
Integrating Rhetorical and Literary Theories of Genre
}

\section{Amy J. Devitt}

W hile many scholars have addressed the critical issues of whether English can or should hang together as a field politically, economically, and culturally, I address in this article the issue of whether we in English studies can hang together topically - that is, whether we can see ourselves as sharing a common object of study. It is obvious that different subdisciplines of English have different methodologies, from hermeneutic to social scientific, that raise different questions and are based in different ideologies. If these subdisciplines have no more in common with one another than do the studies of history and literature, or philosophy and composition, or psychology and linguistics, then the question of whether English constitutes a discipline is strictly a political question and need only be discussed in political terms, a question answerable in terms of political expediency or public perception more than in terms of disciplinarity. If, however, the fields of literature, linguistics, and rhetoric-composition share more in common with one another than they do with other disciplines, then a greater argument can be made that we in English should work to maintain our connections, for our different methodologies and questions can complement and contribute to one another's research and teaching.

What we in English would seem to have in common is the study of discourse, especially of text, although the definition of "text" varies. If that common object of study is significant, then our separate examinations of it should combine to create greater understanding of the complexity of reading and writing. To examine that claim, I will compare and attempt to integrate the scholarship on one part of

Amy J. Devitt is Associate Professor of English at the University of Kansas, where she teaches courses in writing, English language, and rhetoric-composition. Her current research emphasis is on genre theory, and she is working on a book-length theoretical overview of genre as well as collaborating on a firstyear writing textbook based in understanding genre. Her book, Standardizing Written English: Diffusion in the Case of Scotland 1520-1659, was published by Cambridge University Press, and she has published articles in $C C C$ as well as chapters in several collections.

College English, Volume 62, Number 6, July 2000 
discourse-genre-from two subdisciplines of English, literary and composition study (with the latter's theory of genre drawing heavily from linguistics). To some extent, of course, we must maintain our theoretical differences in order to achieve our disparate goals and discoveries. Within rhetoric-composition, genre scholars working from the systemic functional linguistics of $M$. A. K. Halliday emphasize and hence learn about different aspects of genre from those working with Bakhtinian dialogism or Russian activity theory. Yet such theoretically different scholars in rhetoric-composition still attend to one another's work in order to learn more about genre, to discern areas inadequately investigated, or to gain perspective on their own work. So, too, should rhetorical genre scholars and literary genre scholars attend to one another's work. If the study of literary discourse shares more with the study of rhetorical discourse than just political expediency and departmental name, then extending this cooperative dialogue can help both literary and rhetorical genre theories advance in new, productive directions. We may not be capable of developing a single, unified theory of genre-we may not even want the simplification necessary for such a unified theory — but the search for such a theory can enlighten us about our commonalities as well as about genre.

\section{A Brief Redefinition of Genre: RHETORICAL AND LITERARY}

Both literary and rhetorical genre theories have a long history, and both have recently begun developing new conceptions of genre. Genre has been a significant concept for both literary and rhetorical study at least since Aristotle, who defined literary kinds in The Poetics and delineated the kinds of oratory in On Rhetoric. The traditional notion of genre that developed after Aristotle, however, treated genre as a formalistic classification of types of texts. Redefinitions of genre have been developing within rhetoric-composition since the 1980s, drawing from Halliday's systemic functional linguistics, Bakhtin's dialogism, and more recently Anthony Giddens's structure theory and Russian activity systems. The work developing from these different theorists (and others) has taken quite different directions, ranging from studies of how children learn narratives (e.g., Kress) to the ideologies underlying scientific articles (e.g., Bazerman Shaping). Such different approaches and objects of study have helped genre theory in rhetoric-composition develop a sophistication and complexity of perspective. Underlying most such work, however, is a core of agreement about the social and rhetorical bases of genre. Often deriving their definition from Carolyn Miller's use of Halliday and Lloyd Bitzer in "Genre as Social Action," new rhetorical genre theorists tend to agree in treating genre as typified social action rather than as conventional formulas, as rhetorical use of symbols in frequently encountered contexts in order to accomplish writers' and readers' purposes. 
Miller's original definition of genre as "typified rhetorical actions based in recurrent situations" (159) has been complicated considerably by rhetorical genre theorists, including questioning the nature of recurrence and making the interaction between genres and context reciprocal (e.g., Schryer, Berkenkotter, Huckin, and Devitt, "Generalizing"). Although I will not attempt here to amplify this definition of genre, ${ }^{1}$ examples demonstrate that people use genres to do things in the world (social action and purpose) and that these ways of acting become typified through occurring under what is perceived as recurring circumstances. Within established genres, what are seen as formal conventions have developed as rhetorical acts and continue to act rhetorically. People divide lab reports into sections, thereby easing readers' ability to find needed information and reinforcing scientific views of knowledge. Journal articles define/create a gap in existing research and then act to fill that gap. Business memoranda state their purposes in the first paragraph, and readers scan that first paragraph for essential information. In fact, genres are defined less by their formal conventions than by their purposes, participants, and subjects: by their rhetorical actions. Genre, as redefined in rhetoric-composition in complex and myriad ways, is defined by its situation and function in a social context.

In some ways, such a functional, rhetorical, and social view of genre, based largely on the study of discourse operating in a pragmatic world, seems foreign to an understanding of literary genres, works of art whose functions often seem either obvious or irrelevant. One of the great divides between literature and rhetoriccomposition - the study and valuing of what are considered extraordinary texts versus the study and valuing of everyday texts-appears prominently in this rhetorical reconception of genre. But this social and rhetorical theory of genre, drawing heavily from the questions, issues, and objects of study of rhetoric, fits neatly with some current views of literature, especially those deriving from new historicism and cultural studies, and it offers new insights into the traditional literary genres.

Today, literary studies, like rhetorical studies, is renewing its interest in genre by reconceiving the nature of genre. Literary scholars from comparative literature, cultural studies, historical studies, and other current schools of literary theory have been revisiting genre and restating its centrality to literary study. In The Power of Genre, published in 1985, Adena Rosmarin argues that genre can be reclaimed as a literary critic's tool. Ralph Cohen, in "History and Genre" in 1986, contributes to a treatment of literary genre as dynamic and changing. Marjorie Perloff, in 1989, edited Postmodern Genres, providing a forum for major scholars to examine genres of all kinds, both literary and nonliterary, textual and nontextual, in light of postmodern epistemologies. In 1993, David Fishelov published his study Metaphors of Genre: The Role of Analogies in Genre Theory to survey past and recent genre theories in order to recover what could still be useful for the understanding of literary genres today. And the concept of ideology, which has become so central to much of literary theory, was 
connected to literary genre in 1994 in Thomas O. Beebee's book, The Ideology of Genre: A Comparative Study of Generic Instability. Clearly, genre has once again become a significant concept for literary study, and literary theorists are recreating their views of genre to accommodate current approaches to literature. Those recreated views of literary genres are easily compatible in some ways with recreated views of rhetorical genres, ${ }^{2}$ but each also raises questions for the other.

\section{Similar Questions, Similar Answers: Genre as Present, Varying, And Dynamic}

Since literature and rhetoric-composition, like other fields of knowledge, have been affected by common philosophical shifts, it is not surprising that their preconceptions of genre share many qualities, qualities that can form the bases of a shared understanding of genre. Most of the scholarship on genre, however, fails to recognize the commonalities across different works. Text and textual meaning, whether literary or rhetorical, are not objective and static but rather dynamic and created through the interaction of writer, reader, and context. Although literary theorists tend to emphasize the relationship of the reader and the text while compositionists tend to emphasize the relationship of the writer and the text, our common understanding of genre begins with the interactive nature of textual meaning, the rhetorical triangulation of writer/reader/text, and the embeddedness of those relationships within context or culture. These complex and complementary intersections can lead to new understandings of genre. Were genre to be defined as static categorization or static textual features, genre would hold little significance for today's theorists, whether from literature or rhetoric-composition. Instead, genre can be redefined in all these text-based fields as a dynamic concept created through the interaction of writers, readers, past texts, and contexts.

Because genre is part of the cultural context within which writers and readers work, genre-like culture and context-is inescapable. If scholars do not agree with E. D. Hirsch's all-encompassing statement that "All understanding of verbal meaning is necessarily genre-bound" (76), they might agree with Jacques Derrida's more paradoxical statement, "[E]very text participates in one or several genres, there is no genreless text; there is always a genre and genres, yet such participation never amounts to belonging" (65). Many rhetorical genre theorists draw on Bakhtin's definition of utterance as always interacting with other utterances or Halliday's embeddedness of every utterance within a register to assert that all texts are generic. Literary genres may seem more obviously to be participating without belonging, but, in agreement with current rhetorical genre theory, literary genre theorists (other than Croce and his followers) have largely rejected the romantic notion that literary texts escape genre, that the "best" literary works are those that cannot be categorized, 
those that no genre can hold. (That the best literary works still "go beyond" our expectations for genre is another argument that is addressed later in this article.) Fishelov describes the relationship of even the most innovative literary works to genre in a way that echoes rhetorical views of creativity within genres:

... even in those areas of modern literature where it seems that generic rules are absent, the innovative areas of canonic literature, generic rules are still a vital part of the literary communicative situation. These generic conventions might be viewed as a challenge, or a horizon, against which the writer and his reader have to define themselves. The writer may stretch the generic rules, he may produce some unpredictable 'match' between different existing conventions of existing literary genres (or even between literary conventions and conventions taken from other media), but in order to understand the overall significance of his text, we should be aware of the generic system against which he is working. A writer does not create in a textual vacuum, and a rebellious child is still part of the family. (82-83)

As this comment suggests, a contemporary genre theory must also shift away from traditional genre theory by emphasizing the nature of genre as difference as well as similarity. We know genres by what they are not as well as by what they are; a text participates in genres that it rejects as well as in those it accepts, in genres that it avoids as well as those it embraces. In rhetorical genre theory, Anne Freadman asserts that rhetorical genres must be defined by "not-statements." In literary study, Rosmarin describes genres as metaphors, a move that I see as thereby encompassing both likeness and unlikeness (as the metaphor "my love is a rose" derives meaning both from including the rose's perfume and from excluding the rose's thorns). Beebee goes so far as to argue that " $\mathrm{a}$ 'single' genre is only recognizable as difference, as a foregrounding against the background of its neighboring genres" (28). Cohen makes a similar argument in explaining why genres need not be defined by shared generic traits:

A genre does not exist independently; it arises to compete or to contrast with other genres, to complement, augment, interrelate with other genres. Genres do not exist by themselves; they are named and placed within hierarchies or systems of genres, and each is defined by reference to the system and its members. A genre, therefore, is to be understood in relation to other genres, so that its aims and purposes at a particular time are defined by its interrelation with and differentiation from others. ("History" 207)

As Beebee points out, this complex interaction at the heart of current genre theory is also at the heart of our rejection of formalist genre theories, for "formalism is limited to describing what is 'there' in the texts, whereas any generic reading of a text is based equally on what is not there, on what the text does not say, and ultimately on what cannot be done with it" (263).

Since genres are defined by such similarity and difference, texts must not only always participate in a genre but always participate in multiple genres simultaneously. 
Thus, texts need not be categorized singularly, as either tragedy or comedy, for example, or simply, as "genre writing," such as mysteries, romances, science fiction, and westerns. As a result of genres being defined by what they are not as well as what they are, Beebee argues, "every work involves more than one genre, even if only implicitly" (28). Perloff argues that more recently developing postmodern genres appropriate multiple genres, "both high and popular," by "longing for a both/and situation rather than one of either/or" ("Introduction" 8), but Beebee argues that all genres, not just postmodern genres, involve such multiplicity: "Genre must be defined recursively: genres are made out of other genres" (264). Similarly, Kathleen Jamieson, in rhetorical studies, demonstrates that historically particular genres have derived from antecedent genres, and hybrid genres are created from existing genres. Texts are generic in multiple and complex ways.

The making of genres is thus situated in specific historical circumstances, making genres dynamic and responsive to change. Cohen offers the most elaborated dynamic and historical theory of literary genres: "[G]enre concepts in theory and practice arise, change, and decline for historical reasons," ("History" 204). He sees generic grouping as a process, classifications "undertaken for specific purposes" (205). Thus, genres "are historical assumptions constructed by authors, audiences, and critics in order to serve communicative and aesthetic purposes.... Groupings arise at particular historical moments, and as they include more and more members, they are subject to repeated redefinitions or abandonment" (210). New historical literary scholars in particular have demonstrated the historical situatedness of literary genres in such works as Janice Radway's on romance novels. Rhetoricians such as Charles Bazerman, in his in-depth study of the research article, have found rhetorical genres richly enmeshed in historical circumstance and particularity as they adapted to their times. The historical and institutional ${ }^{3}$ situatedness of genres makes them essentially ideological, as Beebee argues at length for literary genres and as rhetoricians have demonstrated in many studies of professional genres (for example, see Pare on social workers' reports or Schryer on veterinary medical records).

\section{Similar Questions, Different Answers: Genre as Constructed and Constructing}

Both literary and rhetorical genres are thus conceptual rather than formal, and those generic conceptions encompass multiplicity and difference as well as similarity. Genres are historical, institutional, cultural, and situated. To develop these common perspectives from disparate theories does not require simplifying or stretching either literary or rhetorical genre theory. But underlying this apparent agreement may be a more essential disagreement about the nature of genres. Rhetorical genre theory tends to be based in a functional, pragmatic theory of textual meaning. Genres help 
language-users achieve certain aims, fulfill certain functions, perform certain actions, and do things with language. To the extent that genres are "successful" in achieving those functions, even as situations and participants change, readers and writers operate within them. Even "unsuccessful" genres can operate on readers and writers if the genres have become calcified or their proponents have sufficient status and power in the group that uses them. Genres "exist," then, in the sense that they are patternings from repeated actions according to which (or in reaction against which) readers and writers use language. Can literary genres be understood as functional and pragmatic in the same way? Do literary genres "exist" and operate on readers and writers in the same ways? I would answer yes, but some literary theorists have answered the same questions differently.

These differing definitions of the nature of genre's existence are revealed especially in the genre theory offered by Rosmarin. To Rosmarin, genres "exist" only in the critic's mind and in the critic's use of them. The critic, not the writer, defines the genre (29). From Rosmarin's perspective, genre is a critical tool rather than a language-making tool, or even an operational tool, as rhetorician David Russell would have it. To reduce genre to a tool at all is to deny its conceptual and ideological nature, making genre the consequence of culture and action rather than a part of a recursive and interactive relationship with culture and action. In particular, defining genre as a critical tool makes the critic all-powerful and rhetorical interaction negligible, as Rosmarin herself reveals: "[O]nce genre is defined as pragmatic rather than natural, as defined rather than found, and as used rather than described, then there are precisely as many genres as we need, genres whose conceptual shape is precisely determined by that need. They are designed to serve the explanatory purpose of critical thought, not the other way around" (25). Significant in this passage are Rosmarin's uses of the passive voice and collective "we." Who defines and uses genre? And whose need determines the conceptual shape of genres? To Rosmarin, the answer to both questions is the critic. To rhetoricians, the answer is the writer and reader. In this move to the critic as definer of genre, Rosmarin privileges the reader's role-and a particular kind of reader's role-above all others. ${ }^{4}$

Certainly, some compositionists can sometimes be faulted for privileging the role of the writer over that of the reader, text, or context. Compositionists who focus solely on a writer's expression of self or treat writers as able to create original texts independent of prior genres are producing the inverse of Rosmarin's preference. But capturing the pragmatic nature of genre requires capturing its complex functionality-in the writer's aims, in the culture and society's institutions and power maintenance, in the text's rhetorical strategies, and in the reader's or critic's responsive actions. As Beebee writes, in a different context, "genre is only secondarily an academic enterprise and a matter for literary scholarship. Primarily, genre is the precondition for the creation and the reading of texts" (250). 
As a "precondition" for making meaning through language, genre also has power to shape texts, a power that Rosmarin's view of the critic as generic arbiter would preclude. The critic has power, in Rosmarin's view, to examine any text "as if" it participated in any genre. Only multiple examinations of a text through multiple generic screens yield insight into the text, Rosmarin argues, and the choice of generic screen is limited only by the critic's ability to show that his or her use of a genre best justifies the "value" of a particular literary work (50-51). The necessity of seeing any text as participating in multiple genres is an insight that literary genre theory does seem to offer to rhetorical genre theory, as I discuss further later. However, the critic and her aim to justify literary value are not the only powerful participants in genres; the aims of the writers and the needs of the cultural context must also be taken into account. The text, the writer, the context, and the critic, too, as a reader, are shaped by genre. That is the fuller power of genre.

Although not all literary genre theorists agree with Rosmarin's perspective, her position, though extreme, reflects a common privileging by literary theorists of the critic's role in creating genres. ${ }^{5}$ Of course, that privileging of the critic makes sense for scholars of literature who are most concerned to contribute to the literary critic's interpretative range. But some compositionists have tended to privilege the writer in similar ways and to use the writer's understanding of genre as defining what matters in genre study. Rhetorical genre theory, however, needs to account for what matters to critics, writers, and other readers as well as to understand genre's embeddedness in text and context. If literary genre theory depends on genre being a construction of the critic alone, then rhetorical genre theory will necessarily contradict literary genre theory.

Fortunately for a common understanding of genre, few literary genre theorists agree with Rosmarin's complete preeminence of the critic as definer of genre. Cohen gives writers and other readers a role in genre construction and function, even as he privileges the critic's role. Cohen's privileging of the critic seems more the result of his (and traditional literary genre theorists') interest in enabling literary criticism rather than the result of an exclusive definition of genre. Cohen sees the dynamic nature of genres for all participants, and his emphasis on the social and aesthetic functions of genre leaves room for functions other than the critic's. Among literary genre theorists, Beebee in particular seems to make genre a rhetorical concept encompassing writers, readers (including critics), texts, and contexts. Beebee echoes functional genre theorists rather directly in privileging "use-value" as the essence of genre: " $[\mathrm{A}]$ text's genre is its use-value. Genre gives us not understanding in the abstract and passive sense but use in the pragmatic and active sense" (14; emphasis in original). The use-values that Beebee describes are comfortably familiar to new rhetorical conceptions of genre, involving the functions the genres serve for their users and the contexts in which they operate: "[G]eneric differences are grounded in 
the 'use-value' of a discourse rather than in its content, formal features, or its rules of production" (7). He further argues that, since use-values are necessarily social, genres (and genre theory) are necessarily ideological (14-15). In a detailed examination of how letter-writing manuals evolved into novels such as Samuel Richardson's Pamela and others, Beebee argues that the manuals came to have functions, usevalues, that the original ars de dicta could no longer fulfill, and so they developed differently in order to achieve the genre's functions:

[T] he rhetorical manual must correspond to the social and political circumstances of its readers; it must represent the letter writer in order to produce a good letter. In other words, in order to fulfill the rather explicit function this genre has been assigned, it must do something else beyond the limits of its genre: it must become literature, create a (fictional) excess. In doing so, the ars becomes something other than itself. (110)

Although Beebee appears to be alone among literary genre theorists in defining genres according to their use-values, he is not alone in seeing generic change as originating in social and political change. His argument suggests that rhetorical genre theories based on pragmatic function can account for literary genres as well. In fact, most of Beebee's book demonstrates a literary generic criticism based on such a functional and rhetorical view of literary genres. Cultural studies approaches to literature in general would also seem to accommodate rhetorical genre theories, for cultural studies seem based on rhetorical understandings of how participants use "texts" in cultural contexts and of how the texts and participants are shaped by the contexts. Such detailed genre studies as Janice Radway's study of the romance genre describe literature as fulfilling particular functions for its readers, and other studies of particular literary genres at least make reference to what genres do for their readers and for society. Such current literary studies also can emphasize the ideological nature of genres, as does Beebee, making it easy to see the ideological functions of particular literary genres. For genre theory to encompass both literary and rhetorical genres requires not that literary theorists abandon their attention to the critic's perspective on literature. Instead, our understanding of genre will advance from our separate emphases-on the critic or on the writer-if we can leave room for one another's emphasis and develop complementary concepts.

\section{Different Questions, Similar Answers: Conformity, Variation, and Valuing of Genre}

Another difference of emphasis that a common genre theory will have to accommodate is the emphasis on conformity to or variation from generic expectations. Where rhetorical genre theorists often seek texts that typify a genre, examine writers' conformity to generic conventions, and study readers' roles in promoting 
generic expectations, literary genre theorists are more likely to seek texts that break the rules of a genre, to value writers who violate conventions, and to act as readers promoting unconventional generic readings. ${ }^{6}$ Great authors have often been admired for their "breaking" of generic conventions, thereby expanding the literary universe. Current authors (such as Laura Esquivel or Gabriel García Márquez) and some past authors (such as Lawrence Sterne in Tristram Shandy) are admired for their resistance to generic ideology, often through "appropriating" multiple genres, thereby giving us more "hybrid" genres. Rhetorical genre theory must be able to deal with desirable variations within literary genres made by accomplished writers as well as the mastery of generic conformity by experts and the "errors" in rhetorical genres made by novices.

Describing the variation in individual texts should pose no problem for rhetorical genre theory. Methods of rhetorical criticism already exist to examine the rhetorical effectiveness of accomplished speakers (such as presidential inaugural addresses), methods that correspond to and cooperate with literary critical methods. Even to account adequately for everyday texts, rhetorical genre theorists have argued for the need to embrace a definition of genre that encompasses difference as well as similarity, variation as well as standardization, and creativity as well as conformity (see Freadman, Devitt "Standard," and Christie). Genre theorists need to see genre as both/and rather than either/or, to encompass both the conformity and the resistance, the expected and the surprise, so that we can account for rhetorical and literary genres that themselves encompass both norms and variation. We also need to describe rhetorical and literary texts that both reproduce and resist their genres, a need better met by a genre theory that sees in every text and every genre both similarity and difference.

Yet all texts are not alike in the degree to which they conform to generic conventions, and not all genres are alike in the degree to which they encourage conformity or encourage variation. Some literary genres are seen as highly conventionalized, with specifically defined expectations, compared with less narrowly defined genres-haiku and sonnets compared with free verse, morality plays compared with theater of the absurd, mysteries compared with "literary" novels. While all of these literary genres can be seen, in light of current genre theory, as encompassing both standards and variations, the room for variation would appear to be larger in some genres than in others. The same can be said for rhetorical genres: the expectations for lab reports are more narrowly specified than those for research papers, for résumés more narrowly than for application letters, for obituaries more narrowly than for essays, and for inaugural addresses more narrowly than for resignation speeches. The comparisons are infinite; however, less attention has been paid to different levels of expectation in rhetorical than in literary genres, and rhetorical genre theory would benefit from examining these levels and the effects of more or less specification on writers and readers. 
Even within a genre, some writers "break" or "challenge" generic conventions more than others, a fact more often noted in literary than in rhetorical study. Jane Tompkins includes a personal voice and experience in her journal articles; Hélène Cixous experiments with scholarly form in hers. In literary circles, such experimentation often moves a writer to a "higher" literary realm. Both John Grisham and John Irving write novels, but one is commonly called formulaic, the other literary. Writers who "play" with generic expectations enough are even moved from one genre to another. Formulaic novels are labeled mysteries, for example, but mysteries that "go beyond" the formula are labeled novels (compare Lillian Jackson Braun's The Cat Who ... mysteries to Umberto Eco's novel The Name of the Rose).

The difference of literary status points out another issue heavily emphasized in literary genre study but virtually ignored in rhetorical genre study: the valuing of different variations and different genres. Variation within literary texts is generally more highly valued than is similarity. At times, the value of a literary work seems definable wholly in terms of the work's variation from what others have done, its resistance to what is expected. Of course, literary value is much more complicated than simple surprise value, and the degree to which the unexpected is valued in literature has certainly varied over time as well. Nonetheless, the most highly valued literature is typically valued to some degree for its "originality," its "novelty." Current rhetorical genre theory can show how genre enables creativity, but the study of literary genres demonstrates that it will also need to explain how and why that creativity is valued.

The challenge for genre theory is not just to account for the fact of variation from generic expectations or their different valuations, although that challenge alone is a substantial one. Variation is also valued differently at different times and in different contexts, and, even within one time and context, not all variations are valued alike. In addition to traditional aesthetic theories, recent social theories, critical pedagogy, and cultural studies all show promise in helping to clarify this differential valuation, for each helps us understand value as a cultural construct. New perspectives on ideology, appropriation, and resistance might be especially helpful if generic variation is viewed as generic resistance. As Beebee notes, "if genre is a form of ideology, then the struggle against or the deviations from genre are ideological struggles" (19). Detailed studies of particular literary works in their cultural contexts should be able to reveal the power relationships, prevailing ideologies, and generic expectations that lead to the valuing of particular variations, and comparative historical studies should be able to show how those relationships, ideologies, and expectations change across different cultures and times so that different variations are differently valued. Current redefinitions of literary value, in other words, should also lead to fuller understanding of the value of generic variations and of genre knowledge as cultural capital. 
Such notions of value rarely, if ever, have arisen in rhetorical genre theory, although indifference to questions of value cannot persist in the face of recent turns to critical perspectives on genre (see Freedman and Medway "Locating"). Although some rhetorical genre theorists have been critical of the genres they studied, more common has been a descriptive or historical stance toward the genres studied, a stance that has contributed much to our understanding of how genres work but that now must be supplemented by a more critical stance. Perhaps such inattention to value reflects the focus of some rhetorical genre theorists on the writing of novices, whether students or workers in entry-level positions. Dealing with texts often so little valued, and with generic variations most often viewed as "errors," such scholars have often resisted traditional notions of value in order to claim significance for their objects of study. On another side, genre scholars working with academic, corporate, and governmental genres have aimed first to describe and understand fully the working of less familiar genres or the history of familiar ones. Bazerman (Shaping) sets out to describe the features and history of the experimental article in science, for a notable example, and John Swales works to describe the research article, especially for students for whom English is a second language. The discoveries from such genre research have set the stage now for the kinds of complications that literary genres raise, including the complication of value. Genre theory already examines the roles of genres in the communities that use them; those roles can now be partly distinguished by how the users value those genres. Genre theorists are increasingly taking critical perspectives on genres, including examining how genres maintain or reinforce power relationships and how they shape world views, leading easily to interpretations of generic value in terms of the community's values. The developing notion of genre sets (which I proposed and described in 1991 and which Bazerman elaborated in 1994 in "Systems") can fruitfully encompass differentiations among genres within those sets; some genres will be more highly valued than others. In general, the quality of value can and should be added to the qualities of genres that genre theorists investigate and should be part of the social and rhetorical actions of genre.

\section{Different Questions, Different Answers: Function, Community, and Situation of Genre}

So far, I have argued that questions typically raised in the study of literature can be addressed in rhetorical genre theory, although surely not to the satisfaction of every literary theorist and not always without considerable expansion of existing genre theory. The questions I have raised from literary theory about the nature of genre, its existence apart from the critic, the significance and appreciation of generic variation, and differences in how genres are valued at different times are questions that enrich existing rhetorical genre theories and can lead to significant new areas of research. 
When reversed, however, and literary answers to questions from rhetorical genre are considered, answers do not always come so easily. In particular, rhetorical genre theory raises two questions that are answered about literature only with difficulty: What are the functions of literary genres? What communities do literary genres serve?

Unless they can find a way to claim that literary genres are essentially different from rhetorical genres, rhetorical genre theories based on functionality require that literary genres, too, be describable in terms of their functions for their users. If the genres of scientists perform the work of scientists, what work does literature accomplish? For what group of users? The functions of literary genres have been long debated. Some, such as Bakhtin, argue for a general aesthetic function for literature as a whole. Sir Philip Sidney was not alone in specifying the functions of literature as "to teach and delight" (11). Somewhat more narrowly, Aristotle distinguishes tragedy and comedy not only by their differing subject matter and level of language but also by their differing effects on readers serving different functions for readers. Many literary scholars have puzzled over the function of tragedy for readers who are saddened by reading it, some positing a purging of emotion or a reassurance that other people have worse circumstances. Others have explored the laughter function of comedy, perhaps the classical genre with the easiest association with a function. More difficult has been attaching a function for readers for poetry or the lyric; often scholars have resorted to an expressive function: poetry expresses readers' deeper thoughts and emotions, and it helps readers reflect on their worlds. As the discussion moves from classical genres to what some call subgenres-sonnets, dramatic monologues, novels-the functions of literary genres are described in more particular terms. Sonnets glorify love, monologues enable the poet to comment on the speaker's perceptions, and novels give order to the human condition. More recent and culturally contextualized explanations of literary functions include Radway's description of romances enabling their readers to separate from their familial obligations and reassert their belief in the heterosexual relationship. Though the nature of literary function is far from settled, literary theorists would seem to assume that literature must have functionality, so requiring literary genres to be seen as having functions would not appear to be an obstacle to a common genre theory.

According to rhetorical genre theories, those generic functions exist for a community of users of the genre, both readers and writers, communities defined most narrowly by Swales and more broadly by such theorists as Berkenkotter and Huckin or Russell. Until recently, most rhetorical genre theorists have viewed a genre's community as a relatively coherent group, definable even though it contains novices and experts. But literary communities are not easily delimited. Radway's study of the romance as well as Aristotle's postulates about the effects of tragedy and comedy show how closely generic function can be tied to generic readership, for literary as well as rhetorical genres. As Radway notes, however, even her careful study examines 
only a small number of readers and only one kind of reader. The mothers reading romances at home while their children sleep or attend school are not the same readers as the secretaries reading romances at their desks during lunch or on the subway heading to work. Similarly, the New York philanthropist reading a poem in The New Yorker is not the same audience as the New York poet reading the same poem. Even more so, the playgoer on the floor of the Globe is not the same audience as the Shakespearean scholar studying the Hinman collated manuscript. With such multiple audiences, literary genres can be described in terms of their communities of users only if the community is described always in multiple terms: literary poems are read by other poets, by editors, and by educated readers who aspire to cultural sophistication. Rhetorical genres, too, would benefit from being attached to multiple, interlapping communities: business memoranda are read by the audience specified in the address line and potentially by those readers' staffs, by the writer's peers and bosses, and by anyone else to whom the memorandum is forwarded. While scholars who examine specific rhetorical genres typically do analyze their complicated situation, to account for both the business memorandum and the literary poem we in English would do well always to complicate our understanding of audience and function, to base genres whether literary or rhetorical, in rhetorical situations that are multiple and complex.

Both questions-about the functions and about the communities of literary genres-cause difficulty, in part because of a common quality of some literature: it is read by multiple audiences at different times and places, apart from its initial situation and community. What might in the past have been described as "transcendence" or "universality" permits some literary works to be enjoyed well beyond the initial rhetorical situations and cultural circumstances that first produced them, and, for some literary genres, such transcendence and universality seem to be part of their function.

I can leave to literary scholars and cultural critics the question of why some particular literary works appeal to later readers and other works never surpass their times. Surely much of the question of how and why literary works are read beyond their local situation can be answered by historical study and cultural critique. Different reading publics have developed at different historical periods, with different literary "tastes" and different commercial forces at work to encourage reading some works and even whole genres over others. The issues of value, raised earlier in this article, develop historically and culturally and influence what gets read and how. The fact, then, that some literary works are read centuries after they were written can be explained in historical and cultural terms, without reference to genre theories.

That simple fact, though, still poses difficulty for a genre theory that grounds genres in recurring types of situations. When literary works are read centuries after they were written, the situation within which they were produced has changed. Even 
if we can attach a function and community to a literary genre, as I have argued above we can, can we claim that that function and community have remained unchanged centuries later? A Shakespearean tragedy was written within the drama genre of the time; it is read today within a drama genre that has surely changed, as all genres change over time in response to differing circumstances. We read an essay by Samuel Johnson today within a different set of expectations about essays than his contemporary readers would have had. Of course, we also acknowledge readily that our reading of a Shakespearean play is not the same experience as the viewing of the play by the groundlings in the seventeenth century or that our reading of Johnson's essay does not coincide with how eighteenth-century publicans read it. Reader-response theory would suggest that readers recreate texts in their own contexts, and such an explanation fits easily within rhetorical genre theories. Yet we do say that we are reading the same genre. If genre is tied firmly to rhetorical function and situation, then the genre itself must also be seen as different when experienced apart from its initial function and situation. Catherine F. Schryer establishes an important discovery for rhetorical genre theorists: that genres are never really stabilized, that they are always already changing in response to differing situations, and that they are what she calls merely "stabilized for now." From the evidence of literary texts being read in later times and under different circumstances, I would add that not only the genres but even the generic identity of particular texts is only stabilized for now.

Another apparently simple fact about many literary genres complicates our attachment of genres to function and situation. Part of their function is to transcend particular situations. Even though current views of literature stress their connectedness to local circumstance, some literary genres go beyond local circumstance in a way that business memoranda do not. Yes, we can read business memoranda as if they are universal, but we are not then reading them as business memoranda, for we would be reading them for a different function and from a different context. Yet some literary genres include movement beyond the particular circumstance as part of their function. Poetry written in celebration of particular events, for example, still strives to "go beyond" those events. Maya Angelou's poem written for the inauguration of President Clinton speaks to larger circumstances, to human issues, not just local ones, because that is what the genre of poetry is supposed to do. Certainly some literary genres are intensely locally situated (performance pieces seem an extreme example), though even they may be read differently in future generations. When some literary works are read in different circumstances we can say that they become participants in different genres, but what of the works, such as poetry, that from the start would seem to encompass later audiences and contexts?

In fact, there are rhetorical genres as well that would seem to strive for transcendence of their local situation. Inaugural addresses accompany inaugural poems, and they, too, speak to human issues, strive to inspire actions beyond their local cir- 
cumstances, and speak to future generations. Scholarly articles, for a quite different example, speak to future readers as well, attempting to contribute to a field that will continue past the writer's lifetime. Transcendence, in other words, may not so much be a fact of all literature as a component of the context for some genres, both literary and rhetorical. For both literary and rhetorical genres, then, our attachment to function and context needs to be interpreted loosely. While the genres can be described in terms of their functions within communities in response to particular rhetorical situations, the evidence of some literary genres should remind us to allow those functions and contexts to include not only the present but also the future.

\section{New Questions, New Answers: Genre as Individual, Multiple, and Destabilized}

Even though the questions raised by literary genres are sometimes different from those raised by rhetorical genres, we can, I have argued, develop answers that enrich our understanding of both literature and of genre theory. These answers for literary genres can also complicate and clarify our investigation of rhetorical genres. In particular, this investigation of literary genre theory raises several new possibilities for rhetorical genre theory: focusing on the variation within individual rhetorical texts; examining rhetorical texts as if they participated in multiple rather than single genres; considering whether rhetorical genres might have more complex, multiple functions and situations; and addressing questions of value within and among genres.

Perhaps because literary works have long been studied for their particularities even more than for their commonalities, examining literary genres discourages us from depending too heavily on similarities and points us to differences-differences of one text from its generic expectations and differences of one genre from other genres. Rhetorical genre theory has addressed generic difference as well: Freadman's theory ("Tennis") argues for defining genres in terms of what they are not as well as what they are; Frances Christie explains how genres enable choice as well as constraint; my argument for genre as language standard encompasses variation as well as standardization. Practically, too, rhetorical critics have examined particular rhetorical works of special merit in order to discern how the rhetor responds to the situation in new ways, how the text diverges from the usual or expected, or what particular rhetorical strategies and styles are used. In general, however, rhetorical genre theorists have usually treated particular rhetorical works as examples of generic expectations rather than as individual texts with individual qualities. Typically, multiple samples of a genre are examined in order to understand the generic conventions, to trace generic change, or to discern the ideological underpinnings of a genre. Individual works written by experts are examined for their demonstration of the generic expectations or their effective blending of old and new genres; individual 
works written by students or other novices are examined for their approximations to the generic expectations or their ineffective blending of learned and new genres. Let me exemplify by revealing the limitations in my own research. When I sought to study the genres written by tax accountants ("Intertextuality"), I gathered particular works written by tax accountants in order to establish the participants' generic categories and to learn what I could about how types of texts operated in that community. I examined particular works in order to learn how particular textual conventions, for example, citation of sources, operated in that genre. I did not examine any particular works in order to see how effectively that particular writer used and varied from the expectations of the genre. I did not study a particular work to understand the significance of the variations from generic expectations in that work. Such emphasis on conformity, commonality, and expectations has served rhetorical genre theory well, helping us to develop a better understanding of how genres operate for their participants, and it should continue to serve genre theory well. Examining literary genres in addition to rhetorical genres, however, should remind scholars that particular works are always more than their representation of generic expectations.

As we reexamine rhetorical works for their variation as well as their conformity, literary genre theory reminds us also of the multiplicity of genres in which any text participates. In fact, literary perspectives such as Beebee's should remind rhetoricians and compositionists to beware of identifying any text too closely with a single genre. If genres are recognized in terms of what they are not as well as what they are, then all texts participate in multiple genres and can best be understood in terms of more than one genre. To some extent, rhetorical views of genre have recognized the need for comparative genre work. Scholars have noted the interaction of some genres, how some genres call for other genres-how requests for proposals generate responding genres, for example. More elaborated systems or sets of genres have also been examined. My research on genres used by tax accountants, for example, found that genres operate in genre sets, which a collection of people use to accomplish their aims-in this case, the work of tax accounting ("Intertextuality"). As an illustration, to understand the genre of a letter to a client responding to a tax question, one needs to understand how the letter is distinguished from letters to IRS authorities and other communications with clients and to see how the letter uses the genres of tax code and tax regulations. To understand the one genre well requires understanding all the other genres surrounding it, both the genres explicitly used and the genres implicitly referred to or shaping what the genre is and is not. As Perloff noted, genres need to be understood in terms of both/and. Although close rhetorical analyses often refer to multiple genres surrounding a particular text, and work such as that done recently by Freadman ("Uptake") argues for the impact of related texts and genres on particular texts in other genres, this interaction of multiple genres within a particular text is not a perspective rhetorical genre theory has paid especial attention to. 
The multiple-genre perspective argued for by some literary critics is of a different nature than that of rhetoricians. Literary critics often examine a particular literary work from the perspective of one genre, then another, or multiple genres together. Scholars in Perloff's collection on postmodern genres demonstrate traces of multiple genres in each "text," whether that text be Bob Dylan's songs or poetry by George Brecht. Such critique based on multiple genres would not be unusual in rhetorical criticism if the examined text were extraordinary in some way-an early example of a developing genre, a response to a new situation (for a good example, see Jamieson's study of papal encyclicals and presidential state of the union addresses). But to examine an "ordinary" text from the perspective of multiple genres would question the usual sureness of our generic identifications of texts. We know that a particular text is a letter to a friend and not a memo, or a research paper and not a personal narrative, or an essay and not a diary entry. If rhetoricians were to adopt literary scholars' questioning of genre and application of multiple perspectives, those ordinary texts might be seen in new lights. A research paper can be seen in terms not only of how it fulfills the aims of research papers, for example, but also of how the particular paper draws on other genres of academic and nonacademic writing the student knows, how it reflects the assignment given by the teacher, and how it shares some of the language of the scholarly articles it cites. Some of this kind of work is being done with student writing to see how students use familiar genres to learn unfamiliar genres. But imagine examining non-student writing, a memo written by an English department chair to his or her faculty, for example, to see how it might reflect not only other memoranda but also that chair's letters to friends, how its tone takes from the curtly worded policy it summarizes, even how it might reflect the community's appreciation for literary genres and accompanying literary language. To examine each rhetorical work from the perspective of multiple genres could develop new insights into the essentially interactive nature of all genres. It also could develop an understanding of what Beebee calls "generic instability" as essential to the nature of genres and of particular works. Rhetorical genre theorists have come to speak of genres as stabilized-for-now, based on Catherine Schryer's phrase, but I would argue that genres are never really stabilized. If each text always participates in multiple genres, then even in that text a genre is moving, shifting, and becoming destabilized. Even temporary stability is an illusion of genre theory rather than a reality of genrein-action.

Recognizing inevitable generic instability also requires a significant reconception of generic function and situation. Schryer's amendment to describe genres as stabilized-for-now recognizes a large part of the instability of generic function and situation, but it does not go far enough. Not only do generic function and situation change over time, as Cohen argues, but they are even unstable at a given time. If the Bible can be read at the same time but in different settings as scripture, history, or 
poetry, perhaps its generic function is not as evident as we may have thought. If an inaugural poem inspires some listeners to renew their faith in their president and other listeners to critique the poem's quality, perhaps the genre's situation is not as static as we may have thought. Even such an apparently stable genre as the lab report has different functions for its student writers than for its teacher readers and exists in different situations when it is being composed in notes in the lab, revised by the student at his computer late at night, or graded by the teacher in her office. Since genres and texts truly participate simultaneously in multiple genres, multiple functions, and multiple situations, generic identity, function, and situation are necessarily unstabilized-forever.

\section{A Common Purpose}

The challenge for writers and readers, as well as for theorists, becomes considerably more complicated with generic multiplicity and instability encompassed in genre theory. Writers must work with multiple purposes, as always, but also with the multiple functions resonating in the chosen genres and their genre sets, some of which writers do not consciously select. The notion of using a genre as an operational tool, even when embedded within activity theory as Russell and others do so well, seems far too simple to encapsulate the complex interactions of multiple genres within a given activity system. Writers and readers must enact many genres and must position themselves in multiple situations. Genre scholarship is poised to help explain how they meet such a complex challenge.

Sharing our theories of genre would give us a way of talking with students about the complexity of reading and writing, whether by dead white males of the canon or live Latina females of the writing class. With a shared understanding of what genre is and how it operates, teachers in English departments could help students read and write flexibly, with an eye to the rhetorical function of discourse but without becoming fixed in a single genre or single set of formal conventions. Generic multiplicity and instability make our usual efforts at teaching students how to read and write genres seem far too simple indeed. To teach students the rhetorical and social significance of one genre will require teaching the significance of its genre set and the place of that genre within that set. Even then, any particular writing or reading situation bends that genre set into interaction with other, unanticipated genres from which writers, readers, texts, and contexts draw. In teaching students to read literary works, we already teach them how to use genre knowledge in conjunction with particular texts. We do not ignore the complexity of that interaction. In teaching students to read and write rhetorical works, we can teach them how to use genre knowledge in conjunction with their particular situations, multiple though they may be, without ignoring the complexity of that interaction. If in turn we taught literary works as par- 
ticipating in multiple genres, with functions and situations, we would be closer to teaching students a shared perspective on reading and writing.

A common teaching of reading and writing can motivate our search for a common theory of genre. Our courses in literature and our courses in composition may emphasize different things, but they can depict reading and writing as a common activity. Literature courses may always emphasize the role of the reader, the writer's uniqueness, the text's significant variations from expectations, even literature's transcendence beyond and yet situatedness in local circumstances. Composition courses may always emphasize the role of the writer, the reader as common audience, the text's conformity to expectations, and even the significance of the writer's processes. Both sets of emphases can be understood as only part of the picture of reading and writing. Both sets of emphases can be encompassed within a genre theory that sees genres as involving readers, writers, text, and contexts; that sees all writers and readers as both unique and as necessarily casting themselves into common, social roles; that sees genres as requiring both conformity with and variation from expectations; and that sees genres as always unstable, always multiple, always emerging. If genre theory can encompass the both/and, if genres can remain fluid and dynamic, then perhaps reading and writing can remain interactive and perhaps the discipline of English can remain fluid enough to encompass the multiplicity and instability of its participants. ${ }^{8}$

\section{Notes}

1. It is difficult for me to leave the definition of genre in such simple terms here, for it has been elaborated significantly and substantially. Readers interested in genre theory in particular should not trust this simplified definition, which bypasses major debates in the field, but should instead read some of the essential and more recent discussions of the nature of genre (Bakhtin, Bazerman Shaping, Berkenkotter and Huckin, Devitt "Generalizing," Freadman, Freedman and Medway, Halliday, Miller, Russell, Swales).

2. For lack of a better term, I will use "rhetorical genres" to distinguish certain kinds of texts from "literary genres." While one can debate whether a distinction should be made between literary and nonliterary genres, the fact is that our field of English has traditionally made such a distinction and that distinction has resulted in the quite different fields of literary and composition study. For my purposes here, of seeing whether one genre theory can encompass all kinds of discourse, it is necessary to continue the fiction of a distinction between texts created to achieve a worldly purpose and texts created for an artistic purpose. Throughout this article, I will question those distinctions and cite especially those in cultural studies who challenge them.

3. This dynamic and socially constructed view of genres needs also to be incorporated into descriptions of genres as institutions. Fredric Jameson, for example, states that "Genres are essentially literary institutions, or social contracts between a writer and a specific public, whose function is to specify the proper use of a particular cultural artifact" (106, cited in Fishelov 87, Jameson's emphasis). The institutional view of genres is an old one, for Jameson's definition partly echoes an earlier statement of Wellek and Warren: “The literary kind is an 'institution'-as Church, University, or State is an institution. It exists, not as an animal exists or even as a building, chapel, library, or capital, but as an institution exists. One can work through, express oneself through, existing institutions, create new ones, or get on, so far as possible, without sharing in politics or rituals; one can also join, but then reshape, institutions" (226). 
Today we would argue that one can never "get on" without participating in institutions and that institutions are not quite so separable from their participants. Rhetorical genre theorists using Giddens's structuration theory, most notably Berkenkotter and Huckin, for instance, have argued that the social structures, including institutions, construct the participants in those institutions and are in turn constructed by the participants. Other scholars have described the substantial role of genres in maintaining those institutions (e.g., Bazerman Shaping). Institutions must thus be seen as more dynamic, reshaped by every action taken by its participants, including its participants' use of genres. All institutions are culturally specific, historically determined; even the buildings, the chapels, libraries, and capitals, are culturally defined. So, too, are literary genres viewed today. Perloff states the matter baldly: "[G]enre, far from being a normative category, is always culture-specific and, to a high degree, historically determined" ("Introduction" 7). Although I would argue that genres are both normative categories and culture-specific, Perloff's description of the historical specificity of literary genres agrees well with the local situatedness and cultural embeddedness of rhetorical genres described by rhetorical theorists. Perloff's collection also demonstrates this view; Lindenberger, for example, examines opera, "to show how a genre is rooted in particular institutional frameworks at different historical moments" (31). Genres are thus institutional, but dynamic constructors of as well as participants in institutions.

4. In fact, Rosmarin appears to omit the role of writers in genre construction altogether. She describes what she sees as a traditional "three-way conflict" in which "constitutive or explanatory power is in rapid and alternating succession located in genres, in the particulars of the historical text and context, in the theorist's 'envisioning' of those genres and particulars" (34). Translated to rhetorical terms, Rosmarin's three-way conflict alternates power in the text, the context, or the reader, but not in the writer. Beebee, in fact, describes a similar traditional conflict, but he includes the writer and adds it up to a fourway conflict: "These four stages of generic criticism—genre as rules, genre as species, genre as patterns of textual features, and genre as reader conventions-correspond to the four positions in the great debate about the location of textual meaning: in authorial intention, in the work's historical or literary context, in the text itself, or in the reader" (3). For rhetorical theorists, writer, reader, text, and context define the essence of rhetoric and of genre.

5. Cohen, in his seminal article on "History and Genre," keeps genre rhetorically as well as historically contextualized in his major argument, which he summarizes as follows:

Classifications are empirical, not logical. They are historical assumptions constructed by authors, audiences, and critics in order to serve communicative and aesthetic purposes. Such groupings are always in terms of distinctions and interrelations, and they form a system or community of genres. The purposes they serve are social and aesthetic. Groupings arise at particular historical moments, and as they include more and more members, they are subject to repeated redefinitions or abandonment. (210)

Yet his next sentence reveals his own essential privileging of the critic over all other participants: "Genres are open systems; they are grouping of texts by critics to fulfill certain ends" (210; emphasis added). In a similar move earlier in the article, Cohen emphasizes that genres are processes rather than determinate categories, which are changed by each member that is added to the genre. He continues, "The process by which genres are established always involves the human need for distinction and interrelation. Since the purposes of critics who establish genres vary, it is self-evident that the same texts can belong to different groupings or genres and serve different generic purposes." (204; emphasis added). To Cohen and Rosmarin, and to many other literary genre theorists, genre is a concept created and used by critics foremost or first of all. Even as literary theorists such as Cohen acknowledge the roles of writers and other readers in genre formation, it is the critic whose conception of genre matters, who defines what is of interest to study, who makes genre matter.

6. This oversimplification of the different emphases of rhetorical and literary theorists is not meant to ignore either literary theorists who examine generic expectations nor rhetorical critics who examine the generic deviations of particular texts. There is, of course, a long history of close rhetorical criticism that examines particular rhetorical texts using interpretive methods similar to those used by literary critics. Presidential inaugural addresses, for example, are closely analyzed for the particular aims, rhetorical strategies, and uses and variations from generic expectations they encompass. I am characterizing the approach taken most often by new rhetorical genre theorists rather than that taken by rhetorical critics. 
7. The words used to describe variation from generic convention reveal the differing attitudes toward such variation. Writers are said to "break," "violate," or "flout" conventions. Others "challenge," "push," "expand," or "play with" conventions.

8. I believe that last paragraph in my more optimistic moments. In my more pessimistic moments, few though they may be, I realize that such an idealized, unified view of the compatibility of literature and composition works only if the scholars and teachers in literature and composition choose to be compatible. This article raises several significant differences in how scholars in the different areas view texts, contexts, readers, and writers, and it proposes ways that the differing views can be reconciled. If scholars working in rhetorical genre theory choose not to adapt their genre theory to literary genres, however, it will continue to emphasize function, community, similarity, and singularity in ways that exclude its application to many literary genres. If scholars working in literary theory choose not to adapt their critic-based definition of genre to a user-based definition, they will continue to define genres as classifications designed to serve critics' purposes, and their classifications will exclude rhetorical genres. It seems to me that we in the field of English do indeed have a common object of study, discourse, and compatible though different perspectives on the object of study. But if people in English select the differences over the compatibilities, the work in one field will never contribute substantially to the understanding of the other field. Perhaps the question of our commonality comes down to a political question after all.

\section{Works Cited}

Aristotle. Poetics. Trans. and ed. Gerald F. Else. Ann Arbor: U of Michigan P, 1967.

On Rhetoric: A Theory of Civic Discourse. Trans. and ed. George A. Kennedy. New York \& Oxford: Oxford UP, 1991.

Bakhtin, M. M. "The Problem of Speech Genres." Speech Genres and Other Late Essays. Eds. Caryl Emerson and Michael Holquist. Trans. Vern W. McGee. Austin: U of Texas P, 1986. 60-102.

Bazerman, Charles. Shaping Written Knowledge: The Genre and Activity of the Experimental Article in Science. Madison: U of Wisconsin P, 1988.

. "Systems of Genres and the Enactment of Social Intentions." Freedman and Medway 79-101.

Beebee, Thomas O. The Ideology of Genre: A Comparative Study of Generic Instability. University Park, PA: Pennsylvania State UP, 1994.

Berkenkotter, Carol, and Thomas N. Huckin. "Rethinking Genre from a Sociocognitive Perspective." Written Communication 10 (1993): 475-509.

Bitzer, Lloyd F. “The Rhetorical Situation.” Philosophy and Rhetoric 1 (Winter 1968): 1-14.

Christie, Frances. "Genres as Choice." Reid 22-34.

Cohen, Ralph. "Do Postmodern Genres Exist?" Genre 20 (1987): 241-58.

. "History and Genre." New Literary History 17 (1986): 203-18.

Derrida, Jacques. "The Law of Genre." Trans. Avital Ronell. Critical Inquiry 7 (Autumn 1980): 55-82.

Devitt, Amy J. "Intertextuality in Tax Accounting: Generic, Referential, and Functional." Textual Dynamics of the Professions: Historical and Contemporary Studies of Writing in Professional Communities. Eds. Charles Bazerman and James Paradis. Madison: U of Wisconsin P, 1991. 336-57.

- "Generalizing about Genre: New Conceptions of an Old Concept." College Composition and Communication 44 (1993): 573-86.

. "Genre as Language Standard." Genre and Writing: Issues, Arguments, Alternatives. Eds. Wendy Bishop and Hans Ostrom. Portsmouth, NH: Boynton Cook/Heinemann, 1997. 45-55.

. "Genre, Genres, and the Teaching of Genre." College Composition and Communication 47 (1996): $605-15$.

Fishelov, David. Metaphors of Genre: The Role of Analogies in Genre Theory. University Park, PA: Pennsylvania State UP, 1993.

Freadman, Anne. “Anyone for Tennis?” Reid 91-124. 
_. "Uptake." Presentation, 2nd International Symposium on Genre, Vancouver, British Columbia, January 1998.

Freedman, Aviva, and Peter Medway, eds. Genre and the New Rhetoric. London \& Bristol PA: Taylor \& Francis, 1994.

. "Locating Genre Studies: Antecedents and Prospects." Freedman and Medway 1-20.

Frye, Northrop. Anatomy of Criticism: Four Essays. Princeton NJ: Princeton UP, 1957.

Giddens, Anthony. The Constitution of Society: Outline of the Theory of Structuration. Berkeley: U of California P, 1984.

Halliday, M. A. K. Language as Social Semiotic: The Social Interpretation of Language and Meaning. London: Edward Arnold, 1978.

Halliday, M. A. K., and Ruqaiya Hasan. Language, Context, and Text: Aspects of Language in a Social-Semiotic Perspective. 2nd ed. Oxford: Oxford UP, 1989.

Hirsch, E. D. Validity in Interpretation. New Haven: Yale UP, 1965.

Jameson, Fredric. The Political Unconscious: Narrative as a Socially Symbolic Act. Ithaca: Cornell UP, 1981.

Jamieson, Kathleen M. "Antecedent Genre as Rhetorical Constraint." Quarterly Fournal of Speech 61 (Dec. 1975): 406-15.

Kress, Gunther R. Learning to Write. London: Routledge and Kegan Paul, 1982.

Lindenberger, Herbert. "From Opera to Postmodernity: On Genre, Style, Institutions." Perloff 28-53.

Miller, Carolyn R. "Genre As Social Action.” Quarterly Fournal of Speech 70 (May 1984): 151-67.

Pare, Anthony. "Discourse Regulations and the Production of Knowledge." Writing in the Workplace: New Research Perspectives. Ed. R. Spilka. Carbondale IL: Southern Illinois UP, 1993. 111-23.

Perloff, Marjorie. "Introduction." Perloff 3-10. ., ed. Postmodern Genres. Norman \& London: U of Oklahoma P, 1989.

Radway, Janice A. Reading the Romance: Women, Patriarchy, and Popular Literature. 1984. Chapel Hill \& London: $\mathrm{U}$ of North Carolina P, with a new introduction by the author, 1991.

Reid, Ian, ed. The Place of Genre in Learning: Current Debates. Deakin University: Centre for Studies in Literary Education, 1987.

Rosmarin, Adena. The Power of Genre. Minneapolis: U of Minnesota P, 1985.

Russell, David R. "Rethinking Genre in School and Society: An Activity Theory Analysis." Written Communication 14 (1997): 504-54.

Schryer, Catherine F. "Records as Genre.” Written Communication 10 (1993): 200-34.

Sidney, Sir Philip. Sir Philip Sidney's Defense of Poesy. Ed. Lewis Soens. Lincoln: U of Nebraska P, 1970.

Swales, John M. Genre Analysis: English in Academic and Research Settings. Cambridge: Cambridge UP, 1990.

Wellek, Rene, and Austin Warren. Theory of Literature. 3rd ed. New York: Harcourt, Brace \& World, 1956. 